\title{
LA CONSTRUCCIÓN DEL PAISAJE CRISTIANO DE GALICIA: HACIA LA DEFINICIÓN DE UN MODELO DE TRANSFORMACIÓN
}

\author{
MARCO V. GARCÍA QUINTELA ${ }^{(1)}$
}

Resumen:

\begin{abstract}
El monoteísmo y el universalismo cristianos llevan implícita su difusión por todas partes. Se convierten las personas y sus prácticas, pero también el orden del tiempo y las percepciones del espacio. En el artículo se estudian los procedimientos seguidos para construir el paisaje cristiano de Galicia. La metodología empleada es una combinación de arqueología del paisaje, arqueoastronomía e historia de las religiones. Se aprecia una reutilización coherente de los paisajes paganos preexistentes, sobre todo de la Edad del Hierro celta, sin que ello suponga una subordinación de la Iglesia sino, por el contrario, un reaprovechamiento del pasado desde una posición dominante.
\end{abstract}

Palabras clave: Galicia, cristianización, cultura celta, arqueología del paisaje, arqueoastronomía, historia de las religiones, Edad del Hierro, Antigüedad Tardía.

\begin{abstract}
The making of the galician christian landscape: towards the definition of a model of transformation Monotheism and Christian universalism aim to be spread everywhere. People and practices become Christian, but also the order of time and the perceptions of space. In our work we study the procedures implemented to build up the Christian landscape of Galicia. The methodology is a combination of landscape archeology, archaeoastronomy and history of religions. We can detect a coherent reuse of pre-existing pagan landscapes, especially those of the Celtic Iron Age, but this does not imply the subordination of the Church but, o the opposite, a reading of previous landscapes from a dominant position.
\end{abstract}

Keywords: spolia, reuse, early medieval churches, constructive techniques, roman altar, social elites

Received: 31 October, 2014; Accepted: 15 April, 2015

\section{LA DIFUSIÓN DEL CRISTIANISMO COMO PROBLEMA HISTÓRICO}

El cristianismo tiene una fecha de fundación: la predicación de Jesús de Nazaret en Palestina en tiempos del emperador Tiberio que le llevó su condena a muerte en la cruz cuando Poncio Pilato era procurador de Palestina (Tácito, Anales, 15, 44). Forma parte del cristianismo la comprensión de sí mismo como una práctica y creencia fundada, esto es, con un origen marcado por coordenadas espaciales y temporales evidentes dentro de la tradición cristiana, aunque resulten difíciles de ajustar con el proceso histórico general debido al sesgo rigurosamente teológico de los textos cristianos más antiguos (el Nuevo Testamento).

Tampoco se discute que tras el concilio de Jerusalén, celebrado hacia el año 50 (Hechos 15, Gálatas 2), se produjo un salto cualitativo cuando los seguidores de Jesús aceptaron que los no judíos podían adoptar el cristianismo sin asumir todas las normas del judaísmo, especialmente la circuncisión. Esta decisión permitió la transformación del cristianismo en una religión universal, universalista $\mathrm{y}$, dentro de la tradición judía de la que procede, monoteísta. Esta situación tiene dos consecuencias.

La primera es que hay un antes y un después para que cualquiera pueda considerarse cristiano tanto a título personal a través del bautismo como mediante la existencia de una comunidad de creyentes que surge en una situación histórica determinada. La adopción del cristianismo siempre tiene una fecha, aunque no la conozcamos. La segunda es que la conversión a una religión monoteísta supone un cambio más profundo que la asunción de una serie de creencias y prácticas. Ello se debe a que la lógica de las religiones politeístas y la lógica de un sistema monoteísta son radicalmente diferentes.

Estas ideas son tan obvias en la cultura occidental cristiana que es preciso ponerlas en perspectiva para entender la magnitud $y$ complejidad del cambio cultural que supuso la introducción del cristianismo. Subrayemos dos aspectos.

En primer lugar, las religiones de la antigüedad carecen de fecha de fundación. Griegos o romanos practican su religión porque así lo hacían sus antepasados. Es cierto que Heródoto (II, 53) decía que Homero y Hesíodo habían precisando las funciones y epítetos de los dioses griegos, pero tenía dificultades para situar a esos poetas en la historia. Roma también tenía una fecha de fundación, pero sus dioses eran anteriores, así Rómulo rinde culto a Júpiter y a otros dioses. Por lo tanto el cristianismo tiene plena conciencia de su

${ }^{(1)}$ Laboratorio de Patrimonio, Paleoambiente y Paisaje, IIT - USC. 
historicidad, al contrario que las religiones politeístas. El cristianismo sabe además que se construye a partir de un antes politeísta para iniciar un ahora cristiano vigente hasta el Juicio Final.

En segundo lugar, las religiones politeístas son compatibles entre sí aunque presentan pormenores específicos. Y sabemos que atenienses y romanos tenían unas normas estrictas para aceptar en sus respectivas ciudades el culto a los dioses ajenos. Pero en las prácticas no había incompatibilidades, por ello carece de sentido decir que un griego politeísta se convierte al politeísmo romano o viceversa. Cuando Ovidio compone en su poesía las tramas de los mitos griegos dando a los personajes nombres latinos no actúa como un converso, como tampoco lo hace un galo sometido a Roma que rinde culto a dioses en los que se mezcla su tradición con nuevos dioses romanos. Sin embargo el cristianismo y el politeísmo son incompatibles. No se puede ser "un poco monoteísta", como explica el Antiguo Testamento.

Estas diferencias entre el politeísmo y el cristianismo plantean una pregunta de tipo histórico y sociológico para entender la difusión y el triunfo del segundo: ¿cuándo y cómo se introduce el cristianismo? Sin embargo hay otra pregunta tal vez más anodina cuya pertinencia intentaremos mostrar ¿dónde se introduce el cristianismo? La respuesta obvia es "en todas partes", pero esas "partes" son lugares poblados por grupos humanos de cultura, estilo de vida, estructura social y religión diferentes. $\mathrm{Si}$ constatamos la diversidad de los grupos humanos cristianizados entre la Antigüedad y la Edad Media (y hasta nuestros días) es evidente que para profundizar en la conversión al cristianismo debemos interrogarnos sobre el dónde. Porque no es igual la Atenas donde San Pablo pronuncia su sermón a un dios desconocido (Hechos 17, 16-34) que la asamblea de los guerreros islandeses que aceptó el arbitraje de un sacerdote pagano, Thorgeir Thorkelsson, que les llevó a convertirse al cristianismo el año 999 (GRøNLIE 2006: 7-9).

La relación entre el cómo y el dónde se establece mediante el concepto de "pagano". Isidoro de Sevilla (556-636) señalaba que los gentiles, los no creyentes, acostumbraban a establecer santuarios (luci) y estatuas (idola) en lugares agrestes y en los campos (pagi), de donde paganus (Isidoro de Sevilla VIII, 10). Incide en esta idea De correctione rusticorum de Martín de Dumio (510-579) cuando trata de prevenir la contaminación de la práctica cristiana en el medio rural con adherencias religiosas ajenas. Estos textos ofrecen una percepción cristiana del mundo en que la dicotomía politeísta-cristiano se desdobla en la dicotomía rural-urbano y, por consiguiente, el problema es cómo se transforma ese paisaje poblado por santuarios e ídolos en otro regido por claves cristianas.

En estas páginas intentaremos comprender este problema en una Gallaecia romana caracterizada por sus pocas ciudades y de escasa entidad. Sólo destacaban Lucus Augusti, Bracara Augusta, Asturica Augusta, Auria (Ourense), Aquae Flaviae (Chaves), Tude (Tuy) y otros pocos enclaves, no muchos, que sin ser ciudades propiamente dichas tuvieron cierta entidad (Brigantium, Vigo...) (PÉREZ LOSADA 2002). En este contexto, la cuestión de la difusión del cristianismo se concreta en saber cómo se cristianiza a partir de esas ciudades un mundo rural poblado por seguidores de religiones politeístas y cuándo se produce ese hecho (DÍAZ Y DÍAZ 1992; ARMADA PITTA 2003; NúÑEZ GARcía \& CAVADA NIETO 2001).

Considerando la información disponible la primera pregunta es más pertinente porque encauza la respuesta a la segunda: malamente podemos poner fechas a un hecho no identificado. Además es más difícil de explicar cómo se produce una transformación intelectual que fijar una fecha, aunque sean necesarias técnicas sofisticadas como el carbono 14 o la termoluminiscencia. Además es importante destacar que la cristianización no es un proceso cerrado, que hay cristianizaciones sucesivas marcadas por la aparición de nuevas formas de culto introducidas con el paso del tiempo y que, a veces, nos resultan accesibles.

Intentaremos explicar ese proceso a partir de ejemplos tomados de la mitad occidental de la actual provincia de Ourense. Es difícil decir si algo semejante se produjo en otros lugares de Gallaecia, sobre todo porque, como veremos, el proceso se caracteriza entre otras cosas por la diversidad de los matices. La idea central del argumento es explicar cómo se construye un paisaje cristiano. Conviene pues explicar el sentido de esta expresión.

El término construcción remite a la temporalidad, al hecho de que hasta cierto momento no se practicaba esta forma de religión y que, desde entonces, se difundió hasta alcanzar el estatus de religión única. El paisaje aparece por exclusión pues carecemos de testimonios literarios que nos expliquen cómo tal o cual comunidad rural de Gallaecia adoptó el cristianismo; sin embargo contamos con un territorio que habla "en cristiano", un territorio balizado por una toponimia santa que se expresa de forma redundante y plural a través de las advocaciones de las parroquias y de múltiples materializaciones del culto. Por lo tanto para responder a la pregunta ¿cómo se construye un paisaje cristiano? debemos comenzar por preguntarnos cómo estudiar la religión en el paisaje. 


\section{2. ¿CÓMO ESTUDIAR LA RELIGIÓN EN EL PAISAJE?}

Para responder proponemos una metodología asentada en tres soportes: la arqueología del paisaje, la historia de las religiones y la astronomía en la cultura. Además aplicamos ese método a partir de la consideración de que los cultos cristianos tienen una estratigrafía que permite distinguir entre antiguos y recientes, lo que no quiere decir que sepamos dar una fecha precisa a cada manifestación. Veamos qué aportan estas aproximaciones.

La arqueología del paisaje explica cómo se presentan ante nuestra mirada los elementos que conforman un espacio dado (por ejemplo, TILlEY 1994; CRIADO BOADO 1999). Esto quiere decir que no parte de una premisa temporal ni privilegia un tipo de huella arqueológica. Pongamos un ejemplo.

$\mathrm{Si}$ nos situamos sobre la cima de una montaña de Galicia desde la que se aprecie un horizonte amplio veremos de forma inmediata las formas naturales, montes, valles, ríos, entretejidas con múltiples huellas de acción humana: aldeas, labradíos, bosques... alguna iglesia, un pazo, algún castro recortado en el horizonte. Todo eso lo aprehendemos en el presente aunque sepamos que cada elemento observado tiene una fecha distinta: desde la mámoa neolítica hasta los modernos galpones de uralita. La arqueología del paisaje añade a esta percepción la definición de los patrones de regularidad: el castro está en un alto y la aldea en el valle junto a los campos trabajados, aunque el perfil del castro estará difuminado por la maleza o una masa boscosa producto de la repoblación forestal de la segunda mitad del siglo XX. Las iglesias parroquiales estarán en el centro de la aldea, pero capillas u oratorios se levantan en cualquier sitio. Es decir, la arqueología del paisaje identifica los modelos de uso del territorio construidos por las sociedades humanas a lo largo del tiempo, esos modelos fueron cambiando pero, al mismo tiempo, los restos de cada modelo pretérito, abandonados o reutilizados, forman parte del paisaje en cada presente sucesivo, en cada nuevo modelo. Nuestro problema, por lo tanto, es identificar el modelo de paisaje sobre el que intervienen los primeros cristianos.

En cuanto a la historia de las religiones, ya se ha indicado la diferencia entre politeístas y monoteístas. Además la disciplina enseña que las religiones politeístas priman la práctica sobre la doctrina, el rito sobre la fe. Se pertenece a tal religión, incluso a tal etnia en sentido etnográfico, porque se realizan las prácticas prescritas por la tradición. Recordemos que una de las acusaciones que llevaron a Sócrates a la pena de muerte es que no "practicaba" el culto a los dioses como los demás atenienses (Platón, Apología, 24 b-c; Jenofonte, Memorables, I, 1,1). También es una constante de los sistemas politeístas la conciencia de que cada acción humana, fenómeno natural o rincón del territorio, puede entenderse como el resultado de una acción divina, o está presidido por una presencia divina que puede dejar una huella material muy variada. Ante un mundo religioso tan complejo el cristianismo adoptó una diversidad de estrategias adaptadas a las condiciones de cada lugar (DOWNDEN 2000) y que, para simplificar, pueden reducirse al pacto o a la ruptura. Estas estrategias son constantes como se aprecia, por ejemplo, en la cristianización de América (LAFAYE 1977). Nuestro problema consiste en identificar los restos materiales que responden a un uso religioso en el período que nos interesa e identificar su patrón de distribución. Seguidamente se trata de averiguar si la práctica cristiana responde en estos lugares a una pauta de compromiso, de rechazo, o a algún matiz entre ambas posiciones.

Para identificar esos patrones de uso del paisaje la astronomía en la cultura se revela como una herramienta muy interesante. Se ha explicado en otro lugar el sentido de esta disciplina en relación con los estudios del paisaje (GARCÍA QUINTELA \& GONZÁLEZ GARCÍA 2009). En cualquier caso, es fácil entender que en paralelo con la cristianización del espacio tiene lugar la cristianización del tiempo. Podemos evocar, dentro de nuestro ámbito temporal y geográfico, la diatriba de Martín de Dumio contra la práctica de dar nombres de dioses paganos a los días de la semana (Correctione rusticorum 8-11 y 16). Pero estas observaciones también eran pertinentes antes de la implantación del cristianismo con connotaciones a veces sencillas (la fijación de los solsticios) y otras más complejas (los equinoccios, fiestas de media estación de tradición celta o fenómenos lunares). Por ello concluimos que la astronomía en la cultura (1) relaciona ítems arqueológicos y/o naturales, que de otra forma sería imposible relacionar, considerando los desplazamientos de los astros sobre el horizonte; (2) aporta un abanico de fechas calendáricas con su correspondiente carga cultural pre- y post-cristiana; (3) el conjunto de esa dinámica constituye una fuente histórica.

Por último consideramos la historicidad del cristianismo porque la cristianización del paisaje no se produjo de una vez. Es un proceso acumulativo desde el primer cristianismo hasta la actualidad y podemos entender los testimonios disponibles como las fichas de un diccionario del cristianismo gallego caídas de un archivador y desparramadas por el suelo. La Iglesia da sentido a esas fichas como administradora de su tradición y porque las virtudes de los santos a los que se rinde culto son inmanentes a la Iglesia debido a que su función ejemplarizante trasciende a la fecha de introducción de su culto. Sin embargo como historiadores intentaremos ordenar cronológicamente esas fichas utilizando los procedimientos de la crítica histórica (sabemos que el culto a los mártires 
se implanta en fases tempranas), de la arqueología (que nos permite fechar construcciones dedicadas al culto) y de la historia del arte (con las periodizaciones estilísticas)

Lo ideal es combinar los métodos, pues si bien el culto a los mártires tiene una fecha definida, siempre es posible levantar o rehacer un lugar de culto dedicado a un mártir después de su período de vida. Además las advocaciones cambian, algunas quedan relegadas y otras se renuevan. Las fechas de celebración de los santos también cambian, a veces debido a circunstancias locales. Por eso es importante contrastar la evidencia que proporciona el culto con los análisis sobre los restos materiales.

Pero también, y como veremos enseguida, observamos cómo se acoplaron cultos cristianos sobre los modelos territoriales preexistentes. Ocurre así que la capa cristiana primitiva, identificada según la metodología histórico-crítica, da respuestas sobre todo a la introducción y difusión del cristianismo a partir de las ciudades según modelos generales bien conocidos en la Antigüedad Tardía. Sin embargo, al ocuparnos del mundo rural, observaremos cómo ese cristianismo primitivo parece adaptarse en algunas ocasiones a un patrón simbólico propio de la Edad del Hierro, identificado mediante la arqueología del paisaje. Es decir los interrogantes planteados y las metodologías desplegadas para resolver ambas cuestiones, autónomos como punto de partida, convergen para apoyarse en sus conclusiones.

De esta forma tres problemas históricos (la identificación de un patrón de implantación religiosa de la Edad del Hierro, la cuestión de la difusión del cristianismo en el medio rural y la definición del conocimiento astronómico propio de diversas épocas) y tres métodos diferentes (la arqueología del paisaje, la crítica histórica y arqueológica de fuentes, y la observación astronómica), confluyen para tratar de responder a la cuestión de cómo se construye el paisaje cristiano en Gallaecia.

En todo caso esta no es la única metodología posible. Como hemos indicado siempre es pertinente el estudio crítico de los textos o la mitología comparada. Nos hemos detenido en la explicación anterior por su novedad en relación con los métodos tradicionales que conservan su importancia y a los que recurriremos de forma complementaria.

\section{LA RELACIÓN ENTRE CASTRO Y SANTUARIO EN LA EDAD DEL HIERRO Y SU CRISTIANIZACIÓN}

Comenzamos presentando tres agrupaciones de elementos arqueológicos formadas por grandes castros y conjuntos de arte rupestre ${ }^{1}$. Los primeros se conocen como oppida, para distinguirlos de los castros ordinarios de menor tamaño (GONZÁLEZ RUIBAL 2006-2007: 2, 328-49), que aparecen en el norte de Portugal y Sur de Galicia en la segunda Edad del Hierro. La relación de los oppida con estaciones de arte rupestre revela una gran coherencia en la pequeña muestra que manejamos (y que es preciso ampliar) porque, además, la relación entre castros y grabados se cristaliza con eventos solares en fechas significativas (Fig. 1).

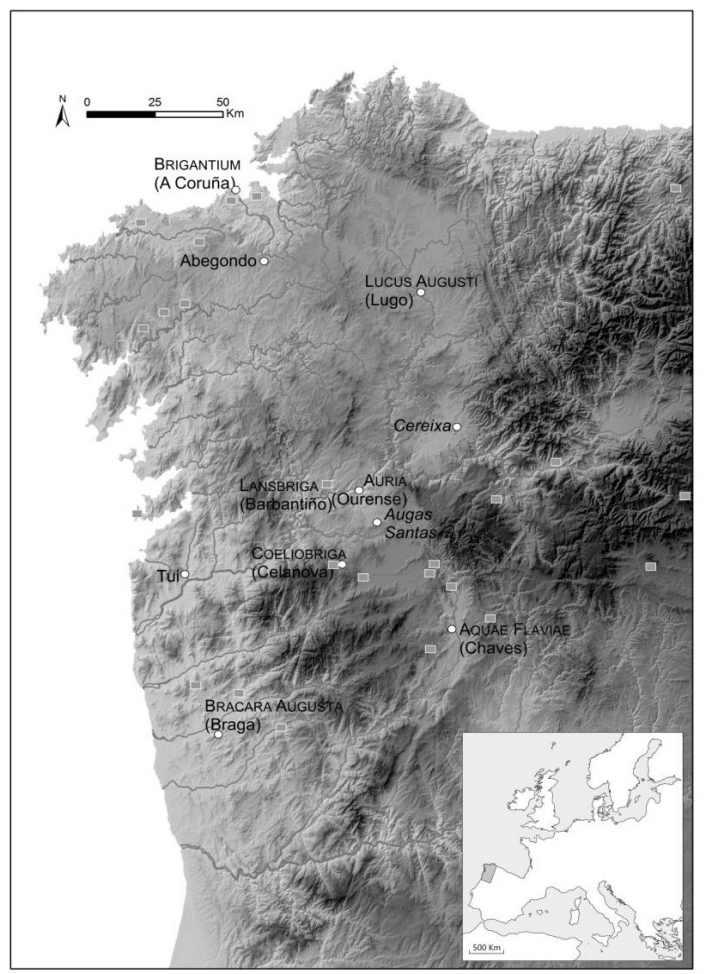

Fig. 1. Puntos Blancos: obISPAdos tardo-antiguos de Gallaecia y otros lugares mencionados en el texto. Rectángulos grises: topónimos en -briga, indicadores del uso de lengua celta (algunas localizaciones son aproximadas).

Fig. 1. White dots: Gallaecian bishoprics from Late Antiquity and other places named in the text. Grey rectangles: place names including - briga (hill, high place) indicating a Celtic origin (some locations are approximate).

\footnotetext{
${ }^{1}$ Se discute la datación del arte rupestre de Galicia. El punto de vista tradicional distingue dos períodos, la Edad del Bronce y grabados genéricamente considerados "históricos" (PEÑa \& VÁzQueZ 1996: 100-106; PeÑa SANTOS \& Rey GarCía 2001: 104-119; CARRera Ramírez et al. 2002: 68-74) a partir de que están atestiguados en tiempos históricos (FerRo Couselo 1952). Los trabajos de M. Santos y colaboradores (SANTOS Estévez 2007, 2008; GARCía QuinTELA \& SANTOS ESTÉVEZ 2008; CRIADO BOADO et al. 2013), identifican la singularidad de los grabados de la Edad del Hierro. Es importante señalar las diferencias de método entre ambas posiciones. La tradicional se basa en la identificación crono-cultural de los objetos representados. La segunda se basa en análisis de estilos, patrones de localización según la arqueología del paisaje y dataciones de C14 para Campo Lameiro. Por otra parte abundan indicios de que los grabados, con independencia del momento de su talla, se reutilizaron a lo largo del tiempo, a veces durante milenios (FERRO COUSELO 1952; GARCÍA QUINTELA \& SANTOS ESTÉVEZ 2008; García QuinTEla \& SEOANE VeIGa 2011)
} 


\subsection{San Cibrán de Las y A Ferradura}

Nuestro primer ejemplo se sitúa en la confluencia entre el río Miño y su afluente el Barbantiño (Fig. 2). Es un nudo de comunicaciones natural entre la cuenca del Miño y el Norte de Galicia utilizado desde la prehistoria hasta la actualidad (GARCÍA QUINTELA \& SANTOS EsTÉVEZ 2008: 231-287; DE BERNARDO \& GARCÍA QUINTELA 2008: 263-4; SEOANE VEIGA et al. 2013; GARCÍA QUINTELA et al. 2014).

Durante la Segunda Edad del Hierro domina la zona el castro de San Cibrán de Las. Se construyó con la configuración visible en la actualidad a mediados del siglo II a.n.e. y se abandonó a fines del siglo I de nuestra era. Presenta una planta elíptica de unas 10 ha asentadas sobre una cresta de tal forma que su mitad occidental domina la meseta inmediata y su mitad oriental el valle del Barbantiño muy estrecho y profundo. En el centro del castro una acrópolis amurallada de 1 ha tiene una función religiosa tal como lo atestiguan inscripciones en escritura latina con dedicatorias a un dios romano como es Júpiter $(I O V I), \quad$ o indoeuropea prerromana, BANDUA $L A N S B R I C A E$, que proporciona el nombre celta del castro (Lansbriga), o que muestran la coexistencia de hablantes de la lengua conocida como "lusitano" y de "celta" (SADU VLADU y NABIA // ABIONE). La puerta occidental de la acrópolis está orientada al ocaso del solsticio de verano y presenta una disposición heterogénea con respecto al trazado urbano.
Mirando desde esa acrópolis hacia el NE, a 4,5 $\mathrm{km}$ en línea recta, sobre la margen izquierda del río Barbantiño se sitúa la estación de grabados rupestres de A Ferradura con una tipología que en otro lugar se ha definido como "santuario" (GARCÍA QUINTELA \& SANTOS ESTÉVEZ 2008). Está conformada por unas treinta rocas grabadas de entre las cuales destacan tres con relaciones solares. O Raposo es un abrigo rocoso en cuyo interior una roca con un grabado está orientada hacia una ventana natural que apunta al ocaso en el solsticio de invierno, cuando el sol está en la cima del castro de San Trocado (abandonado en la Segunda Edad del Hierro y 1,5 km al sur del castro de San Cibrán). A Ferradura, homónima con la zona, es una gran roca con multitud de grabados donde destacan los podomorfos y una grieta transversal que apunta a la acrópolis de San Cibrán de Las, al otro lado del valle, y por donde se pone el sol a principios de febrero. Finalmente en A Zarra otro abrigo presenta un grabado en su interior que solo se ilumina en la puesta de sol del solsticio de verano, pero no conocemos elementos arqueológicos relevantes en el punto del ocaso del sol.

Las relaciones de intervisibilidad y solares entre el castro de San Cibrán y los petroglifos de A Ferradura que hemos descrito sugieren que el conjunto debe entenderse como un sistema que se extendía por el conjunto de la cuenca del Barbantiño con otras manifestaciones. En todo caso, ahora nos

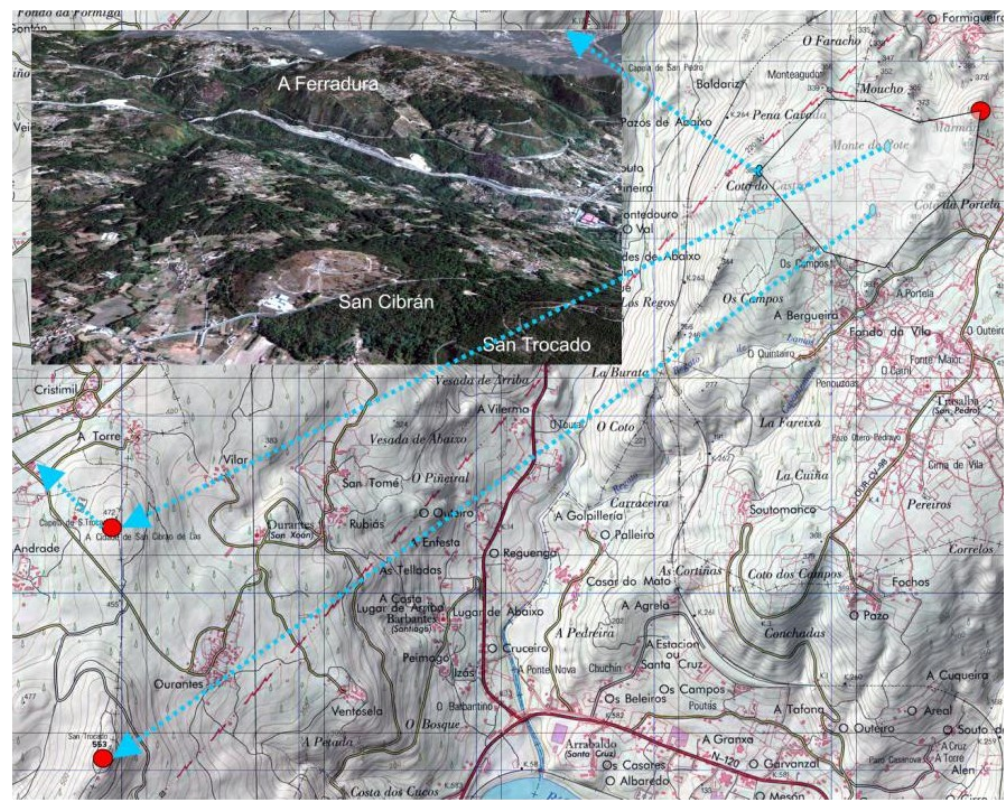

Fig. 2. Paisaje de la Edad del Hierro del Barbantiño. Los puntos rojos son castros, los óvalos azules petroglifos con alineaciones solares. Las flechas azules indican las alineaciones solares. La forma irregular en el ángulo superior derecho es el área de A Ferradura. En el recuadro vista tridimensional del valle del Barbantiño desde el SE sobrevolando San Trocado y el castro de San Cibrán, excavado, al fondo la zona de A Ferradura.

Fig. 2. Iron Age landscape of the Barbantiño River. The red dots indicate hill forts, while the blue ovals indicate rock carvings with solar alignments. The blue arrows show the solar alignments. The irregular form at the top right is the Ferradura rock carvings area. The inset shows the 3-D view of the Barbantiño valley from the SE and over the San Trocado hill fort, the excavated hill fort of San Cibrán, and in the background the area of Ferradura. 
interesa saber cómo se produjo la cristianización de este paisaje considerando los testimonios cristianos más antiguos disponibles.

En el Barbantiño la pequeña aldea de Formigueiro, inmediata con la estación rupestre de A Ferradura, tiene la Candelaria como fiesta patronal. Es relevante señalar como indicio de la reutilización de restos de la Edad del Hierro por el cristianismo en este lugar que durante años (probablemente siglos) la pequeña capilla de Formigueiro tuvo como piedra de altar el reverso de un singular relieve castreño que actualmente figura en su portada tras la restauración del edificio (GARCÍA QUINTELA \& SANTOS ESTÉVEZ 2008: 236-237; Fig.
3). La Candelaria conmemora la purificación de María tras el nacimiento de Jesús vinculando, así, el 25 de diciembre con el 2 de febrero. La noticia más antigua sobre la fiesta en el occidente romano se lee en la crónica del viaje a Tierra Santa de Egeria en el siglo IV. Sin entrar en el tema del origen galaico de Egeria, sabemos que su libro figuraba en las bibliotecas monásticas de Gallaecia durante la Alta Edad Media (DÍAZ y DÍAZ 1997: 328-329). Además son importantes los nombres de lugar vinculados con santos cristianos antiguos: San Trocado (1 de mayo), San Cibrán (14 de marzo) y la dedicatoria de la parroquia de Trasalba, donde se ubica A Ferradura, a San Pedro (29 de junio).

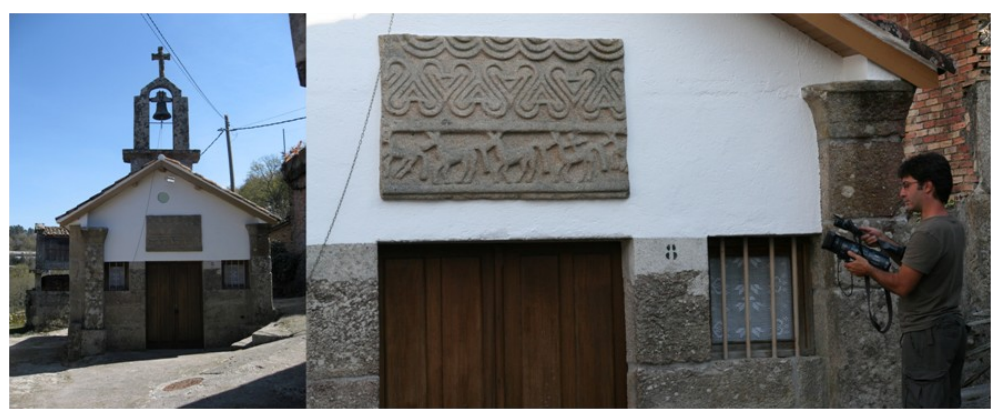

Fig. 3. Relieve esculpido de la Edad del Hierro reutilizado en la capilla de la aldea de Formigueiro.

Fig. 3. Sculpted Iron Age relief re-used in the chapel of the village of Formigueiro.

\subsection{Armea y Vacariza}

Nuestro segundo ejemplo es el castro de Armea situado en el extremo occidental del cordal montañoso denominado Lombas de Santa Mariña desde donde domina el valle de A Rabeda, por donde discurre el río Barbaña (Fig. 4). Se ha excavado parcialmente una zona que revela una intensa romanización. Tiene una superficie de unas 6 ha y está presidido por una acrópolis situada en la cota más alta. Consiste en una superficie circular de pocas decenas de metros cuadrados acotada por un muro y en cuyo centro tres grandes rocas forman la cima denominada "Outeiro dos Pendóns" (GARcía QuINTEla \& SEOANE VeIGA 2011: 248, 254-6; García Quintela \& SeOANe Veiga 2013: 57-60; GARCÍA QUINTELA et al. 2014)

Desde el castro hacia el este se sitúa la vertiente oeste del Monte dos Canteiros en cuya cima, a 1,3 km de distancia en línea recta hacia el SE, está el petroglifo de A Vacariza que sería un "santuario" relacionado con el castro. Presenta dos podomorfos y herraduras (como el de A Ferradura) y ocho cruces posteriores al siglo XVIII así como orificios destinados a soportar un calvario formado por cruces probablemente de madera $^{2}$. No tiene visibilidad directa con el castro debido a la configuración de la cima del monte, sin embargo huellas de fuego en la roca rodeando los grabados, sin afectarles, parece que pudieron formar parte de las pautas de uso del petroglifo.

Mirando desde el Outeiro dos Pendóns el sol nace el solsticio de invierno por el lugar donde están los grabados de A Vacariza, marcado con mucha precisión por la ubicación, intermedia entre ambos puntos, de la gran iglesia románica dedicada a Santa Mariña en Augas Santas y que alberga la llamada tumba de la santa. Veamos, como en el Barbantiño, los términos de la cristianización primitiva de este conjunto.

El paisaje cristiano está dominado por Santa Mariña, mártir local dotada de una potente hagiografía que santifica cada lugar del territorio (GARCÍA QUINTELA \& SEOANE VeIGA 2011: 244-9; GARCÍA QUINTELA 2014a, 2014b). Su fiesta se celebra el 18 de julio y destaca la llamada Basílica de la Ascensión donde, según esa tradición, sufrió tormento. El edificio es una sauna de la Edad del Hierro vinculada al castro y remodelada como cripta vinculada al recuerdo de la santa durante la Edad Media quedando inacabado el edificio (BLANCO RoteA et al. 2009, BLANCO ROTEA et al. en este volumen). Junto a la omnipresente Mariña destaca el culto a Santo Tomé (21 de diciembre), a quien está dedicada la capilla donde se encuentra la primera fuente santa surgida de la decapitación de Mariña. Además acompañan a la santa en la iglesia parroquial San Blas (3 de febrero; LIMIA GARDÓN1987).

${ }^{2}$ Estas precisiones derivan de la detallada descripción del petroglifo que ofrece el obispo de Ourense Juan Muñoz de la Cueva que escribió sobre la parroquia en libros publicados en 1719 y 1716: menciona la existencia de un calvario, que no se conserva y al que atribuimos los agujeros mencionados, y no menciona las cruces grabadas sobre la roca, por lo que pensamos que son posteriores, al tiempo que da una descripción detallada de otros grabados. 


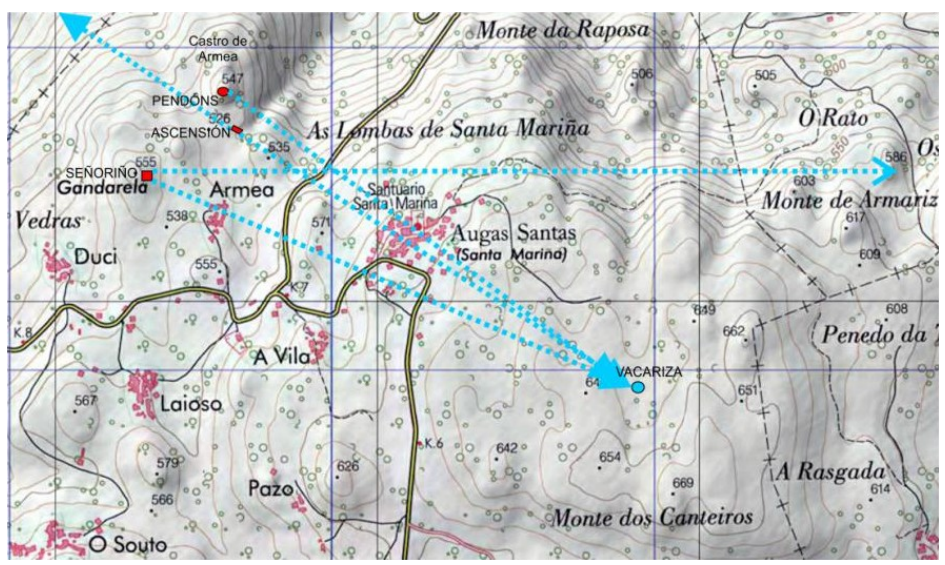

Fig. 4. Paisaje de la Edad del Hierro de Augas Santas. Las figuras rojas indican las estructuras integradas o adyacentes al castro de Armea con alineaciones solares relevantes (flechas azules). El punto azul indica el petroglifo de Vacariza.

Fig. 4. The Iron Age landscape of Augas Santas. The red figures indicate the structures that form a part of the Armea hill fort or which are adjacent to it, with relevant solar alignments (blue arrows). The blue dot indicates the Vacariza rock carving.

\subsection{Castromao y el 'pedrón' de Celanova}

En tercer lugar, el castro de Castromao está situado sobre un monte que domina un sector importante del valle del Arnoia (Fig. 5). Como los anteriores ocupa una ruptura de pendiente de tal forma que su posición es muy destacada sobre el valle situado hacia el norte y el este. Su ocupación se remonta al siglo IV antes de la era. La muralla encierra una superficie de 2,26 ha, pero tal vez era mucho más grande pues se han detectado restos de época romana en una superficie de unas 60 ha. Su nombre antiguo, Koilióbriga, está atestiguado como capital de los Coelerni por Tolomeo (II, 6, 42). Además citan a los Coelerni, mostrando su importancia, una tabula hospitalis fechada en el año 132 de nuestra era encontrada en el castro en 1970, el erudito romano Plinio (III, 4, 28) y la inscripción romana de Chaves conocida como el pedrão dos povos (CIL II 2477), que incluye una lista de pueblos prerromanos situados entre el norte de Portugal y el sur de Galicia (ORERO GRANDAL 2000; NIETO MUÑIZ 2002; GARCÍA ROLLÁN 2004).

En el paisaje arqueológico local destaca, en el valle, un afloramiento rocoso (conocido popularmente como "o pedrón") situado en el patio exterior del monasterio de San Salvador de Celanova, a 2 km en línea recta de la cima castro hacia el SE. En su estado actual esta roca presenta marcas de acción antrópica imposibles de fechar, pero hay testimonios de su uso intensivo a lo largo de los siglos en antiguas historias del monasterio y en representaciones artísticas (GARCÍA QuiNTELA \& SEOANE VEIGA 2011, 249-52).

Entre el "pedrón" de Celanova y Castromao hay una relación solsticial. Desde el "pedrón" el ocaso del solsticio de verano se produce sobre la cima de Castromao. Esto en la actualidad no es visible pues lo oculta la iglesia monástica del siglo XVII y las casas de la villa moderna. Sin embargo es relevante que el inmenso monasterio, construido y re- construido desde el siglo $\mathrm{X}$, mantuvo sus estructuras al sur de la línea solsticial que unía el "pedrón" con el castro. Por otra parte el eje este-oeste del "pedrón" está muy marcado y lo mantiene el oratorio de San Miguel, obra del siglo X, situado entre el "pedrón" y la iglesia monástica. Además desde el "pedrón" el sol nace en fechas equinocciales por la cima del monte de San Cibrán. Si consideramos sólo el "pedrón" esta observación podría no ser pertinente, pero la alineación del oratorio es evidente y dado que está en eje con el "pedrón", parece reutilizar un eje equinoccial preexistente y con relieve cultural o simbólico.

Para la cristianización de Castromao carecemos de una advocación religiosa relevante, pero sobre San Rosendo y la fundación del monasterio de San Salvador en Celanova contamos con la Vida de San Rosendo de Ordoño de Celanova fechado en el siglo XII (DíAZ Y DíAZ et al. 1990). Allí se dice que el culto a San Martín era previo a la fundación (Martín podría ser el de Tours - 11 de noviembre y muy celebrado en Ourense -, o el de Dumio - 20 de marzo y cercano geográficamente). Seguidamente San Rosendo levantó capillas a San Pedro (29 de junio) y a San Juan Apóstol (27 de diciembre) en su condición de testigos de la Transfiguración de Jesús (Mateo, 17, 1-8; Marcos 9, 2-8; Lucas 9, 28-36) que la Iglesia conmemora el 6 de agosto, culto que se conoce también como San Salvador. A estas fiestas se añaden la de San Miguel, a quien se dedica el oratorio del siglo X (29 de septiembre) orientado hacia el naciente en la cima del monte de San Cibrán (14 de septiembre), y la fecha de la fundación monástica (24 de septiembre). San Rosendo también santificó su fundación depositando los restos de San Trocado que estaban en la iglesia de Santa Comba de Bande. El culto a San Trocado se celebraba el 1 de mayo durante el principio de la Edad Media trasladándose más tarde al día 15 del mismo mes. 


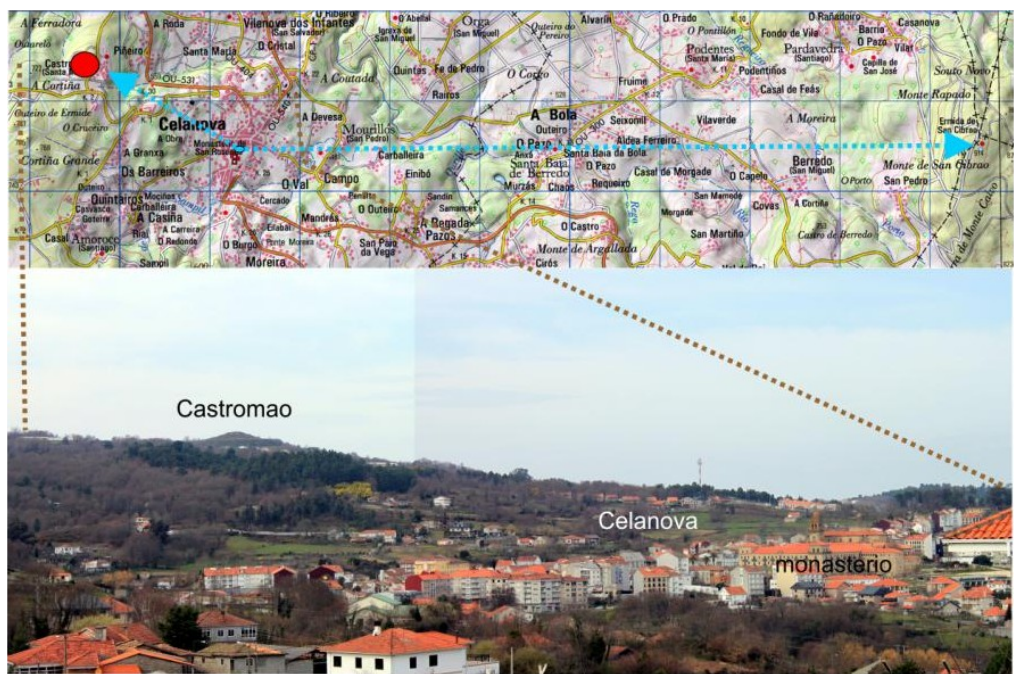

Fig. 5. Paisaje de la Edad del Hierro de Celanova. Arriba, Castromao en rojo y el "pedrón" en azul. Las flechas indican las alineaciones solares. Abajo, vista desde el sur de Celanova con el imponente monasterio de San Salvador y Castromao dominando la línea del horizonte. Las líneas de puntos marrones delimitan la correspondencia entre el mapa y la fotografía.

Fig. 5. Iron Age landscape of Celanova. Top, Castromao in red and the "pedrón" in blue. The arrows indicate the solar alignments. Below, view from the south of Celanova with the impressive monastery of San Salvador, with Castromao dominating the skyline. The brown dotted lines mark the correspondence between the map and the photograph.

\subsection{Un patrón de localización de la Edad del Hierro y su cristianización}

Estas observaciones permiten identificar un patrón de localización de la Edad del Hierro siguiendo la arqueología del paisaje. Los tres castros, pese a sus diferencias, son relativamente grandes y tienen una ubicación topográfica semejante. Además, las acrópolis de San Cibrán de Las y de Armea presentan indicios de función religiosa. Por su parte los "santuarios" rocosos, diferentes entre sí, presentan una localización diversa pero siempre en relación con sus respectivos castros. La pertinencia de esta relación queda demostrada por las alineaciones solares que son parte del patrón de localización de entes arqueológicos que, de otra forma, podrían pasar como ajenos entre sí debido a su heterogeneidad.

Desde el punto de vista de la historia comparada de las religiones cabe subrayar que este modelo dual tiene paralelos en el mundo céltico. Otro paralelo peninsular identificado arqueológicamente es el santuario de Gastiburu (Vizcaya) (VALDÉS 2005) y estructuras semejantes se encuentran en otras zonas de Europa (DE POLIGNAC 1985, 1995; SAUZEAU 2005; GARCÍA QuinTEla 2007). Por otro lado, el texto mitológico irlandés titulado La Fundación del Dominio de Tara presenta la relación entre Tara (la "capital") y Uisnech (el lugar de asamblea) como la existente entre "los riñones de una bestia salvaje” (GUYONVARC'H 1980: 164).

Podemos relacionar estos hechos con el paisaje de la Edad del Hierro identificado considerando dos ideas: se detecta una coincidencia entre las fechas de las alineaciones arqueoastronómicas de la Edad del Hierro y las fiestas cristianas locales y observamos que esa correlación se produce como fruto de lógicas autónomas. Veámoslo con detalle.

En el Barbantiño es evidente la correlación entre la Candelaria, que conmemora el fin de los 40 días de purificación de María tras la Natividad, y las fechas relevantes en la relación entre los grabados de A Ferradura y los castros de la margen derecha del Barbantiño (Fig. 6). Además, si tenemos en cuenta que Egeria da a conocer la Candelaria en occidente a fines del siglo IV podemos considerar que nos hallamos ante la adopción de un punto de liturgia cristiana inspirado por las relaciones temporales preexistentes en el "santuario" pagano inmediato.

En Santa Mariña de Augas Santas es relevante la procesión, atestiguada desde el siglo XVI, que une el día de la Ascensión y el de la fiesta de Santa Mariña la aldea con el Outeiro dos Pendóns, trazando en tierra la relación solsticial entre la acrópolis del castro y el petroglifo de Vacariza y que también recuerda la dedicatoria de una capilla a Santo Tomé (Fig. 7). En este lugar presenta una complejidad especial la Basílica de la Ascensión con refacciones sucesivas y donde ahora podemos recordar que hacia el este, el eje del edificio coincide con los primeros de febrero (coincidiendo con San Blas) y hacia el poniente con la fiesta de Santa Mariña. Si tenemos en cuenta el carácter popular de la hagiografía de Santa Mariña, estamos ante formas locales de creatividad religiosa en torno al culto a los mártires sobre las que se superponen otras formas de culto. 

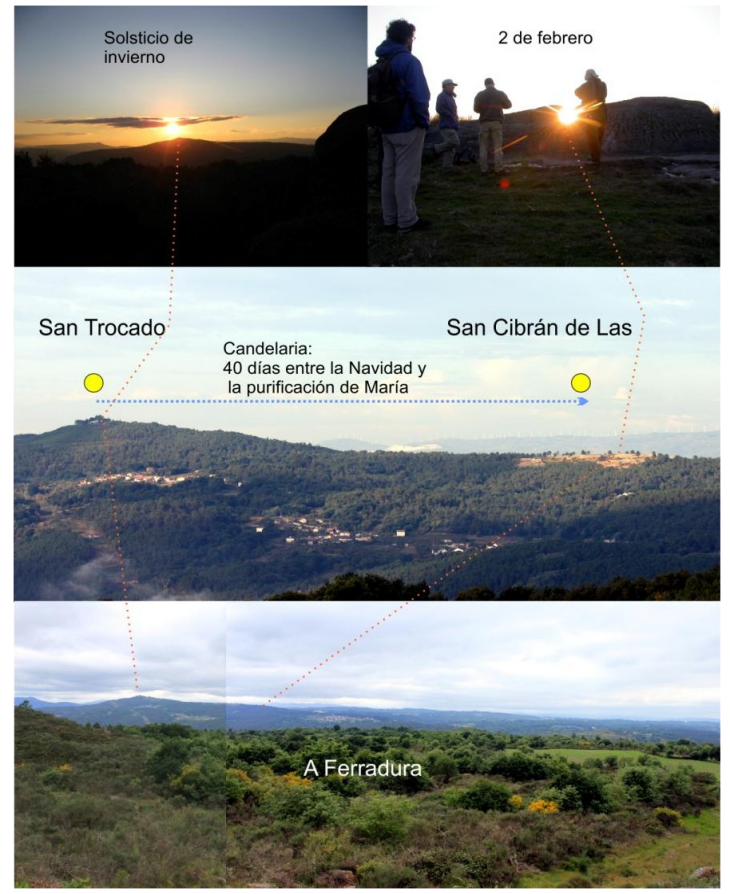

Fig. 6. Cristianización del Barbantiño. Arriba izq.: el sol poniéndose sobre San Trocado el solsticio de invierno visto desde O Raposo; der.: ocaso del sol el 1 de febrero desde el petroglifo de A Ferradura, el sol atraviesa una grieta que apunta hacia el castro de San Cibrán de Las. Centro: desplazamiento del sol en su ocaso sobre el horizonte visto desde A Ferradura entre las fechas solsticiales y el inicio de febrero, esto es, entre San Trocado y San Cibrán, 40 días correspondientes a la purificación de María tras haber tenido a Jesús y que se conmemora con la Candelaria. Patrona de la aldea de Formigueiro vecina a A Ferradura. Abajo, vista general de A Ferradura desde el este, al fondo San Trocado y San Cibrán. Las líneas marrones indican los puntos relacionados en los tres registros.

Fig. 6. The Christianization of Barbantiño. Top left. The sun setting over San Trocado at the winter solstice seen from O Raposo; right: the sun setting on February $1^{\text {st }}$ from the rock carving of A Ferradura, with the sunlight shining through a crack pointing towards the hill fort of San Cibrán de Las. Centre: displacement of the setting sun over the horizon as seen from A Ferradura between the solstice dates and the beginning of February, between San Trocado and San Cibrán: the forty-day period corresponding to the purification of Mary after Jesus' birth commemorated with the Candlemas feast, local patron of the village of Formigueiro, next to A Ferradura. Below: general view of A Ferradura from the east, with San Trocado and San Cibrán in the background. The brown lines indicate the related items on the three levels.

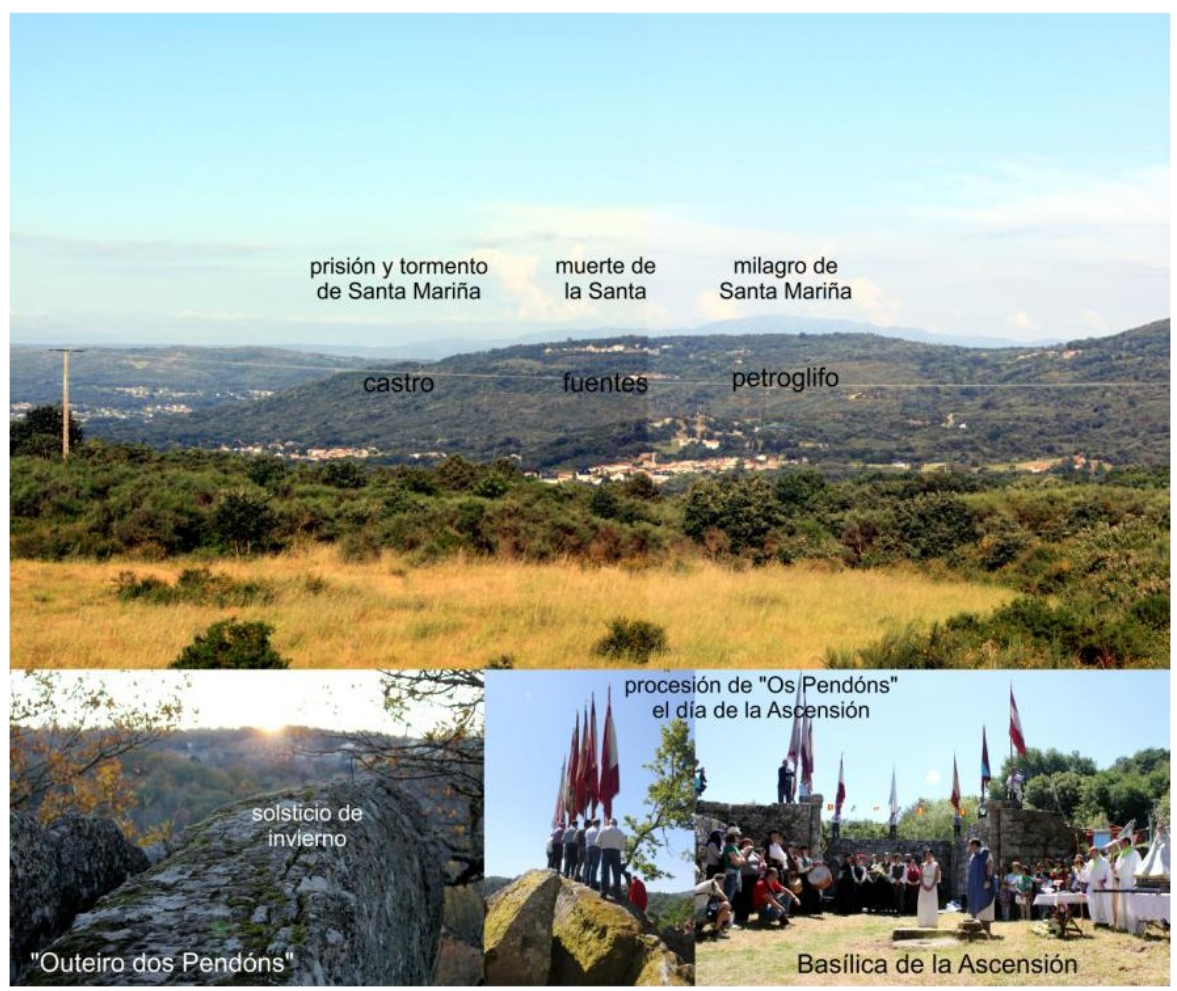

Fig. 7. Cristianización de Augas Santas. Arriba: vista desde el oeste del monte dos Canteiros ocupado por la parroquia de Augas Santas; se indican los puntos arqueológicos y culturales principales y su relación con la hagiografía de Santa Mariña. Abajo izq. nacimiento del sol el solsticio de invierno desde el Outeiro dos Pendóns. Centro: el mismo Outeiro como meta de la procesión "dos Pendóns" que se celebra dos veces al año el día de la Ascensión y el de Santa Mariña (18 de julio). Derecha, representación del martirio de Santa Mariña en la nave de la inacabada Basílica de la Ascensión, por debajo está la cripta donde según la tradición la Santa sufrió el tormento del fuego.

Fig. 7. Christianization of Augas Santas. Top: view from the west of Monte dos Canteiros, comprising the parish of Augas Santas; the main archaeological and cultural sites and their relationship with the hagiography of Santa Mariña are shown. Bottom left: the sun rising at the winter solstice from the Outeiro dos Pendóns. Centre: Outeiro dos Pendóns is where the "Dos Pendóns" procession is held twice a year on Ascension Day and on the feast day of Santa Mariña (July 18). Right: the martyrdom of Santa Mariña is represented in the nave of the unfinished Basilica of the Ascension; below is the crypt where according to tradition, the Saint suffered the torment of fire. 
En Celanova Rosendo presenta su fundación como creada de la nada: Celanova significa "celda [monástica] nueva" y Castromao deriva de Castromagno, relegando el nombre antiguo (Fig. 8). Sin embargo utiliza un elemento de tradición neotestamentaria que encaja con la relación solsticial entre el "pedrón" y Castromao considerando las fechas de celebración de San Pedro y de San Juan Apóstol. Además un complejo elenco de fiestas y toponimia santa subraya la importancia de las fechas equinocciales que mantienen, también, la relación entre el "pedrón" el oratorio de San Miguel y la cima de San Cibrán. En este caso estamos ante una afirmación de la erudición bíblica y monástica en la santificación del territorio.

Hasta aquí nos hemos limitado a presentar hechos y a relacionarlos. Pero además es precisa una evaluación histórica sintética sin obviar los problemas abiertos.

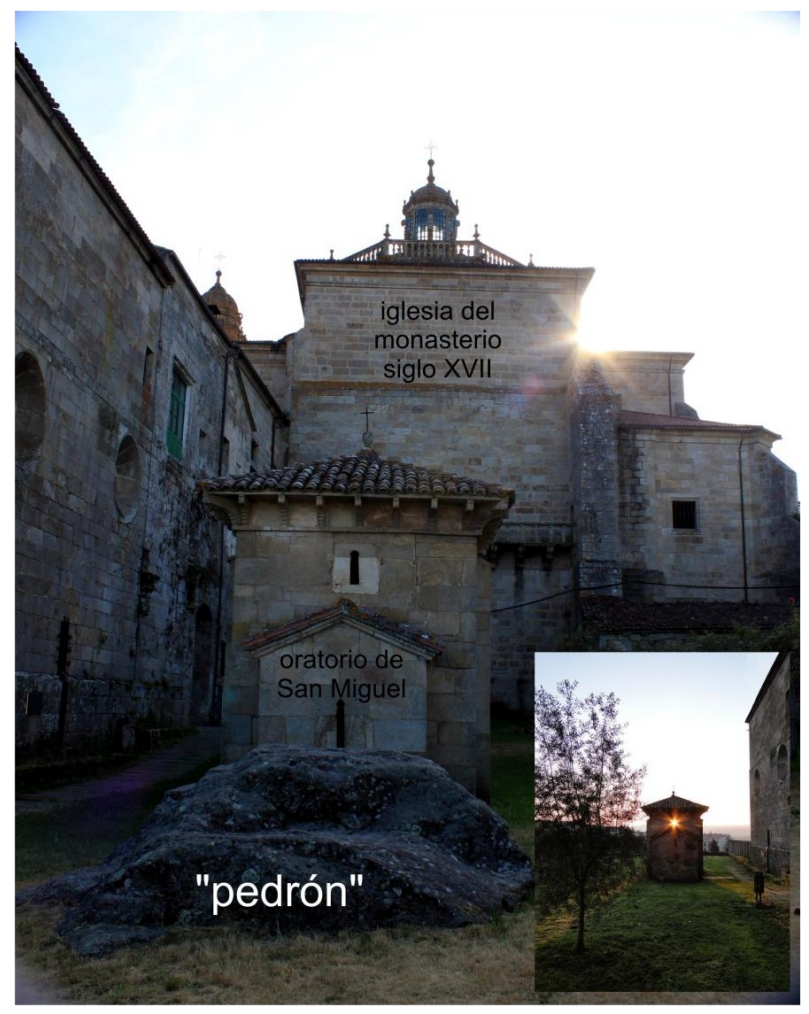

Fig. 8. Cristianización de Celanova. En la fotografía principal se aprecia la secuencia de tres fases históricas de uso de este enclave, el "pedrón", probable "altar" de la Edad del Hierro, el oratorio de San Miguel levantado en el siglo X, cerca de las fechas de fundación del monasterio por San Rosendo, al fondo la gran iglesia barroca. La fotografía se ha tomado en el ocaso del solsticio de verano, cuando el sol se pone sobre Castromao alineado con el "pedrón". En el recuadro el oratorio de San Miguel desde el oeste mirando al nacimiento del sol en el equinoccio, cuando el sol sale sobre el monte de San Cibrán.

Fig. 8. Christianization of Celanova. The main photograph shows the sequence of the three historical stages when the site was in use. The "pedrón" is probably an Iron Age rock "altar"; the oratory of St Michael was built in the $10^{\text {th }}$ century, around the time when the monastery was founded by Saint Rudesind; in the background is the great Baroque church. The photograph was taken at sunset at the summer solstice, when the sun sets over Castromao in line with the "pedrón". Inset: the oratory of St Michael from the west, looking towards the sunrise at the equinox, when the sun rises over Mount San Cibrán.

\subsection{Evaluación histórica}

En primer lugar está el problema de la identidad cultural de la Edad del Hierro. Recordemos que hemos relacionado dos series heterogéneas: un patrón de localización cimentado en observaciones solares y una forma religioso-cultural como es el cristianismo. Pero como parece improbable que los evangelizadores de estos parajes efectuasen un estudio de arqueología del paisaje para definir sus estrategias, debemos pensar que actuaban sobre tradiciones preexistentes ¿es posible identificarlas?
Lansbrigae y Kolióbriga, tienen la forma céltica -briga que indica "altura", o "fortaleza", además en la actual provincia de Ourense están 8 de los 78 topónimos en -briga conocidos en la Península ( 9 ejemplos más en las otras provincias gallegas) (GUERRA 2005: 812-817; GARCÍA ALONSO 2006). Este hecho sugiere que podemos considerar la hipótesis de que se celebraban las fiestas celtas de media estación. Estas fiestas se conocen sobre todo en Irlanda y hay testimonios de su vigencia en otras regiones de la Céltica antigua. Su denominación 
deriva de su celebración cuarenta días después de los solsticios y los equinoccios, sin embargo ignoramos las observaciones que llevaron a fijar esas fechas, aunque sabemos que en Irlanda cristalizaron en su asimilación a las fechas del calendario juliano (cristiano) de los días 1 de noviembre (comienzo del año celta), febrero, mayo y agosto (LE RouX \& GUYONVARC'H 1995). La cuestión para nosotros es saber si algo de esto pudo ser pertinente para los evangelizadores de la zona estudiada.

Sugiere una respuesta positiva que las alineaciones astronómicas de A Ferradura y Armea apuntan a principios de febrero y en ambos casos es relevante el solsticio de invierno. Es decir, parece pertinente la relación entre el solsticio de invierno y la fiesta de mitad del invierno. Por otro lado San Trocado es importante en el Barbantiño y Celanova, coincidiendo su fiesta con la de la mitad de la primavera. En Celanova contamos, además, con las fiestas de San Salvador y de San Martín, próximas a las fechas de mitad del verano y del otoño. Aunque si el Martín pertinente fuese el de Dumio y no el de Tours, en Galicia es posible recurrir a la omnipresente festividad de Todos los Santos el 1 de noviembre.

Toponimia, alineaciones arqueoastronómicas y fiestas cristianas cercanas a las fiestas celtas de media estación sugieren que formas célticas de ordenamiento del tiempo operaron en el trasfondo cultural de este territorio y de su polimorfa transformación cristiana. Pero también es necesario multiplicar observaciones hacia otras partes de Gallaecia porque no debemos ocultar la heterogeneidad de la muestra. En cualquier caso no es prudente enfatizar la idea de continuidad religiosa pues el impacto cristiano es importante. Esto se aprecia en la diversidad de los modelos cristianos seguidos y en la variedad de las formas de situarse la población medieval sobre el paisaje de la Edad del Hierro.

El castro de San Cibrán estaba abandonado desde fines del siglo I de nuestra era, aunque posteriormente tuvo algún episodio de reocupación tardo romana. En Armea el hábitat medieval se dispersó en aldeas situándose la más importante en torno a las fuentes Santas y se reinterpretó el paisaje local en términos de vida, martirio y milagros de Santa Mariña. En Celanova se pretendió romper con el pasado para fundamentar la nueva realidad religiosa en el evangelio y en la primera cristianización de Hispania: según la tradición, San Trocado fue uno de los varones apostólicos venidos de Tierra Santa para acompañar al apóstol Santiago en su evangelización de Hispania y Rosendo, cuando traslada las reliquias de Trocado a su monasterio, estaba enraizando su fundación en la propia Jerusalén. Estas observaciones suscitan interrogantes en dos direcciones diferentes.

Por un lado constatamos que la cristianización se produjo a partir de un patrón de ocupación del territorio establecido en la Segunda Edad del Hierro (en fechas que es necesario precisar). Pero ¿qué ocurre durante el dominio romano? Sabemos que los castros de la muestra están "romanizados", pero siguen siendo castros y, aparentemente, mantienen el esquema religioso-simbólico precedente sin alteraciones ¿cómo se debe entender esto?

Por otro lado, las observaciones arqueoastronómicas apuntan a la vigencia de un calendario de horizonte. Los puntos relevantes están localizados de forma natural con independencia de las construcciones o actividades humanas relacionadas con ellos. La importancia de los solsticios es evidente, contamos con un abanico de fechas equinocciales, sobre todo en Celanova, y aparecen fechas que permiten evocar las fiestas celtas de media estación. Sin embargo se discute el procedimiento seguido por los celtas para fijar esas fiestas ¿Pueden estas observaciones contribuir a la discusión?

Finalmente, las fechas asumidas para el santoral son las gregorianas actuales. Sin embargo es preciso considerar las fechas medievales (lo hemos hecho con San Trocado). Y es preciso, por lo tanto, investigar cómo se produce en cada sitio la relación entre un calendario de horizonte usado por una población de cultura celta, que es reutilizado como base de una cristianización que no es uniforme en sus pautas y que además pasa, a escala local, por el proceso de adaptación de ese calendario de horizonte, que es por tanto un año trópico, a un año litúrgico de base juliana.

Como suele ocurrir, el conocimiento nuevo -la identificación de un modelo de implantación religiosa en la Edad del Hierro de Gallaecia y su reutilización como base para la cristianización-, suscita nuevas cuestiones. En este caso la necesidad de caracterizar mejor el impacto religioso de Roma en el paisaje y un problema técnico de gestión calendárica a través de los siglos.

Pero esta no es la única forma de construir un paisaje cristiano. En efecto, los métodos de crítica histórico literaria permiten identificar otras formas.

\section{PAISAJES LITERARIOS}

Esto ocurre con la historia de Trezenzonio conocida por un manuscrito del siglo XI (DÍAZ Y DíAZ 1985: 95-119). En ella se cuenta cómo el monje Trezenzonio, situado en una Galicia desierta como consecuencia de la invasión musulmana, topó con el faro de Brigantium (la Torre de Hércules). Desde allí pudo ver con ayuda de un espejo milagroso la maravillosa isla de Solistición. Fascinado por la vista emprendió el viaje por mar hasta la isla donde pasó siete años, intentó quedarse pero no lo logró. A su regreso Galicia estaba restaurada y la ciudad de Cesarea casi completamente destruida.

La historia de San Amaro es semejante. El santo tiene una encarnadura histórica complicada lo que no impidió que los relatos en torno a su figura tuvieran una gran difusión en España y Portugal en 
forma de literatura popular (VEGA 1987). La versión gallega de su historia (recogida en Abegondo, A Coruña) presenta rasgos originales (CARRÉ ALDAO 1925). Amaro era un rico heredero que donó todos sus bienes excepto lo que necesitó para fletar una nave en la que se embarcó en busca del Paraíso. En su periplo llegó a una costa desconocida en donde abandonó la nave y su tripulación y emprendió un fatigoso viaje tierra adentro. Tras un tiempo logró una prodigiosa pero efímera visión del Paraíso y tuvo que regresar. El regreso fue fácil pero cuando llegó a la costa todo le resultaba desconocido hasta que le explicaron que estaba en la ciudad de San Amaro construida por los miembros de su tripulación que habían fundado allí mismo una próspera ciudad. Habían transcurrido trescientos años desde su partida. Incide en la popularidad de estas narrativas la historia de San Ero de Armenteira, la versión más antigua está recogida en la Cantiga $\mathrm{n}^{\circ} 103$ de Alfonso X el Sabio, aunque no cita expresamente a Ero.

Los estudiosos de la literatura y el folclore han señalado la semejanza de estos relatos con los immrama irlandeses, viajes al Más Allá emprendidos por monjes como Bran. Existen versiones hispanas de su historia donde recibe el nombre de Brandán, en Galicia, o Borondón (SÁNCHEZ 1997) y paralelos bretones (LAJOYE 2003). La similitud entre estas historias sugiere la existencia de contactos atlánticos entre Galicia y los mundos céltico bretón o irlandés medievales. Pero ciertos elementos heterogéneos permiten pensar que esas historias responden a tradiciones locales de transmisión oral y también de inspiración céltica. Es digna de mención la interpretación por F. Marco de la iconografía de la diadema de Moñes (de la Edad del Hierro) y de la estela de Villar de Sarria (de época provincial romana), como sendas formas de plasmar iconográficamente un viaje de las almas al más allá (MARCO SIMÓN 1994, 2009).

Ahora nos interesa destacar que estas historias construyen el paisaje. En efecto, San Amaro es el nombre de la zona de A Coruña donde está la Torre de Hércules pues esa era la advocación de una pequeña capilla, hoy destruida, situada al sur de la playa homónima. Parece que, en un momento que no podemos precisar, historias y leyendas en torno al Más Allá articularon este lugar adoptando formas diversas pero concordantes a lo largo del tiempo. Además existen numerosas parroquias y capillas dedicadas a este santo en toda Galicia, pero es difícil probar su antigüedad. Sin embargo en A Coruña la confluencia de entre la historia de Trezenzonio junto con la recogida en Abegondo y el nombre tradicional de la zona del faro nos remiten, al menos, a una historia localmente arraigada desde la primera Edad Media.

Hay otra historia de creación de un paisaje cristiano que tal vez podamos remitir a esas fechas. El procedimiento de identificación consiste en este caso en la detección de temas semejantes en dos textos y tratar de discernir sus razones.

Nos situamos en la lagoa Antela junto a Xinzo de Limia. En torno a esa laguna se narraron gran cantidad de mitos. Uno de ellos cuenta que en la ubicación de la laguna había antes una ciudad llamada Antioquía cuyos vecinos eran poco caritativos. Para castigarlos Dios envió a Jesús con la intención de probarlos y Jesús se personó con apariencia de mendigo que pedía limosna en todas las casas pero sólo lo acogió una humilde anciana en su choza donde pasó la noche. A la mañana siguiente Jesús le dijo a la anciana:

"Ven, quero que olles o que foi de Antioquía. E a velliña quedou sorpresa cando viu que no lugar que ocupaba Antioquía estendíase una lagoa que asuagaba o pobo. E nadie se salvara fora da velliña. Na mañanciña de San Xoán, cando o primeiro raio do sol relampra na lagoa, alá abaixo, muy fondo albíscase o campanario da eirexa. E a noite do Natal, ás doce en punto, óuvense cantar os galos". (TABOADA Chivite 1969, 354, su fuente es L. Prieto, Contos populares da Terra: Antioquía, "La Región", Orense).

Leamos a continuación uno de los pasajes del cronista Hidacio (400-469), obispo de Chaves y natural de Xinzo, donde bajo el prisma de su visión apocalíptica del mundo que le tocó vivir describe los efectos de un terremoto en Antioquía de Isauria el año 462 como castigo por no atender el mensaje cristiano. La ciudad fue:

"engullida en una falla de la tierra; solo el obispo de esta ciudad con algunos que le habían seguido, obedeciendo al temor del Señor, se liberó de la muerte; no quedan más que las cimas de las torres que salen del suelo." (Hidacio, Crónica, 215).

Las semejanzas entre el mito de Antela y la noticia de Hidacio son notables. Dios provoca el hundimiento (bajo tierra o agua) de dos ciudades pecaminosas quedando apenas visibles sus torres y salvándose los cristianos. Destaca, también, la homonimia de la ciudad, bien asentada en la tradición local con un juego de falsas etimologías de origen tal vez muy antiguo. Por ejemplo el obispo ourensano J. Muñoz de la Cueva escribe que "es no vulgar conjetura de haberse mudado por corrupción el nombre de Antioquía en el de Antela" (MUÑOZ DE LA CUEVA 1726: 32).

La pregunta inevitable es quién es la fuente de quién: la tradición popular local sería muy antigua e inspiró a Hidacio o el magisterio de Hidacio fecundó al folclore local. Es imposible decidir, tanto más cuando las interferencias entre erudición eclesiástica y el folclore comparten un terreno tan rico y variado como la hagiografía y los púlpitos han servido como intercambiadores de contenidos entre los fieles y el clero a lo largo del tiempo. Algo semejante ocurre 
con otros aspectos de la leyenda de Santa Mariña.

En la tradición gallega esta Santa tiene una homónima. Es la Mariña que da nombre al linaje de los Mariños. F. Delpech ha estudiado su mito a través de sus múltiples variantes en distintas literaturas y tradiciones. En otro estudio se han relacionado esos análisis con la santa homónima (GARCÍA QUINTELA 2014a). Un breve resumen se puede presentar como sigue.

La fundadora el linaje es una bella mujer a la que encuentra un cazador a orillas del mar. Prendado de ella la lleva a su hogar donde conviven y tienen hijos. Pero la mujer no hablaba, el cazador entonces coge al hijo más querido y hace ademán de arrojarlo a un horno. La madre desesperada profiere un aullido que libera su garganta y recupera el habla. Esto da paso a su boda cristiana y al linaje de los Mariños.

La historia de la Santa tiene puntos en común. Nace en Piñeira de Arcos, a orillas de la laguna Antela que ya conocemos, cuando era una hermosa adolescente rechazó al "presidente" romano Olibrio quien para doblegarla la sometió a martirio. Destaca el episodio del Forno que hemos mencionado y finalmente la hace decapitar. Pero su martirio no es en vano porque da nacimiento a la grey de los cristianos de toda la región.

Finalmente, en Irlanda observamos que Boand, la esposa de Elcmar, cometió un adulterio del que nació un hijo. Para ocultar su falta se dirigió a la fuente mágica de Elcmar que tenía la cualidad de detectar la falsedad en una suerte de desafío. Pero la fuente desenmascara a Boand, estalla, la mutila y provoca la huida de Boand perseguida por las aguas y dando origen al río Boyne, el principal de Irlanda, conocido ya en los testimonios antiguos.

Las tres mujeres coinciden en tener una relación difícil con el matrimonio (concubina, virgen y adúltera) pero las tres son fecundas (linaje, cristianos, hijo adulterino) y las tres crean el paisaje social $y$ físico en el que se asientan. Estas observaciones sugieren que tras ciertos aspectos de la historia de Mariña hay mitos recreados por la tradición cristiana. Pero más allá de la verosimilitud de esta aproximación nos interesa subrayar la pluralidad de los métodos implementados y cuáles son los resultados.

La leyenda sobre Antela enlaza con otras partes de nuestro argumento a través de las fechas, pues la ciudad sumergida sólo se aprecia en fechas solsticiales (San Juan y Navidad), con abundantes paralelos en el folclore céltico, y como escenario del nacimiento de Mariña.

\section{DEL DUALISMO SANTO AL PAISAJE CELTA}

El análisis estructural de los mitos también proporciona vías para comprender cómo opera la construcción cristiana de los paisajes. Es conveniente recordar que la ubicación geográfica de los mitos es clave en la aplicación del método estructural (LÉVI-STRAUSS 1973: 175-233) y, además, lo que distingue el paisaje del espacio es que el pri- mero está construido por una mirada culturalmente condicionada que le da sentido, mientras que los segundos tienden a adoptar formas más neutras (aunque sea en apariencia).

X. Ayán Vila (2005) dedicó un estudio arqueológico y etnográfico a la parroquia de San Pedro de Cereixa (Pobra de Brollón). De su complejo análisis destacamos cómo el territorio de la parroquia se articulaba en torno a dos polos (Fig. 9). La carballeira junto a la iglesia parroquial, en el centro de la aldea, era el lugar donde se celebraba la noite dos cepos para conmemorar a San Blas el 3 de febrero, y era también autentico centro de la vida social de la comunidad. Por otra parte, de entre los castros locales destaca el de Alende, dominando el valle, donde se levantaba una capilla dedicada a San Lorenzo, cuya fiesta es el 10 de agosto. Este castro tiene, además, la particularidad de marcar una suerte de frontera imaginaria entre el espacio mágico ocupado por la mourindá, situado al norte, y el espacio de la vida humana ordinaria que gira en torno al valle cultivado del río Saa. Es interesante señalar que la fiesta de la víspera del 3 de febrero consistía en una fiesta del fuego, donde se quemaban los cepos, los tocones de árboles, en un ritual cuyas connotaciones paganas la iglesia trató de atenuar a lo largo del tiempo. Por otro lado, la celebración más importante de San Lourenzo consistía en que en los períodos de sequía del verano los parroquianos, para propiciar la lluvia, acudían a la capilla y bajaban en procesión la estatua del santo hasta la orilla del río donde se bañaba.

Se aprecia, por lo tanto, cómo el paisaje local se articula en una pequeña serie de relaciones duales que atañen a los planos espaciales y sociales (campesinos/mourindá), temporales (3 de febrero / 10 de agosto) aderezados por una oposición de física elemental (fuego y agua). Es además llamativo que en el medio del frío invierno el rito del fuego evoca a su contrario de la misma forma que en medio del verano el rito busca la lluvia. El paisaje simbólico de Santa Mariña de Augas Santas puede comprenderse de un modo análogo.

Los relatos sobre la santa sugieren que tomemos la ladera del monte dos Canteiros, ocupada por la parroquia, como una unidad simbólica. En la cima está el petroglifo de Vacariza rodeado por un muro que lo separa de una eira de mallar gran piedra plana que servía para acelerar la maduración del grano en verano. En la parte más baja está el Forno da Santa (la Basílica de la Ascensión) y las Pioucas. Allí sitúa la tradición uno de los tormentos infligidos a Mariña. Entre esos dos lugares, a medio camino, están las fuentes santas donde San Blas y Santo Tomé acompañan a Mariña. Pues bien, desde los lugares santos de la parte baja del monte (Outeiro dos Pendóns, Forno da Santa) hacia el naciente se evoca a los santos invernales Tomé (21 de diciembre) y Blas (3 de febrero); por el contrario, desde la aldea y hacia el poniente está la alineación de la Basílica hacia día de Sta. Mariña 


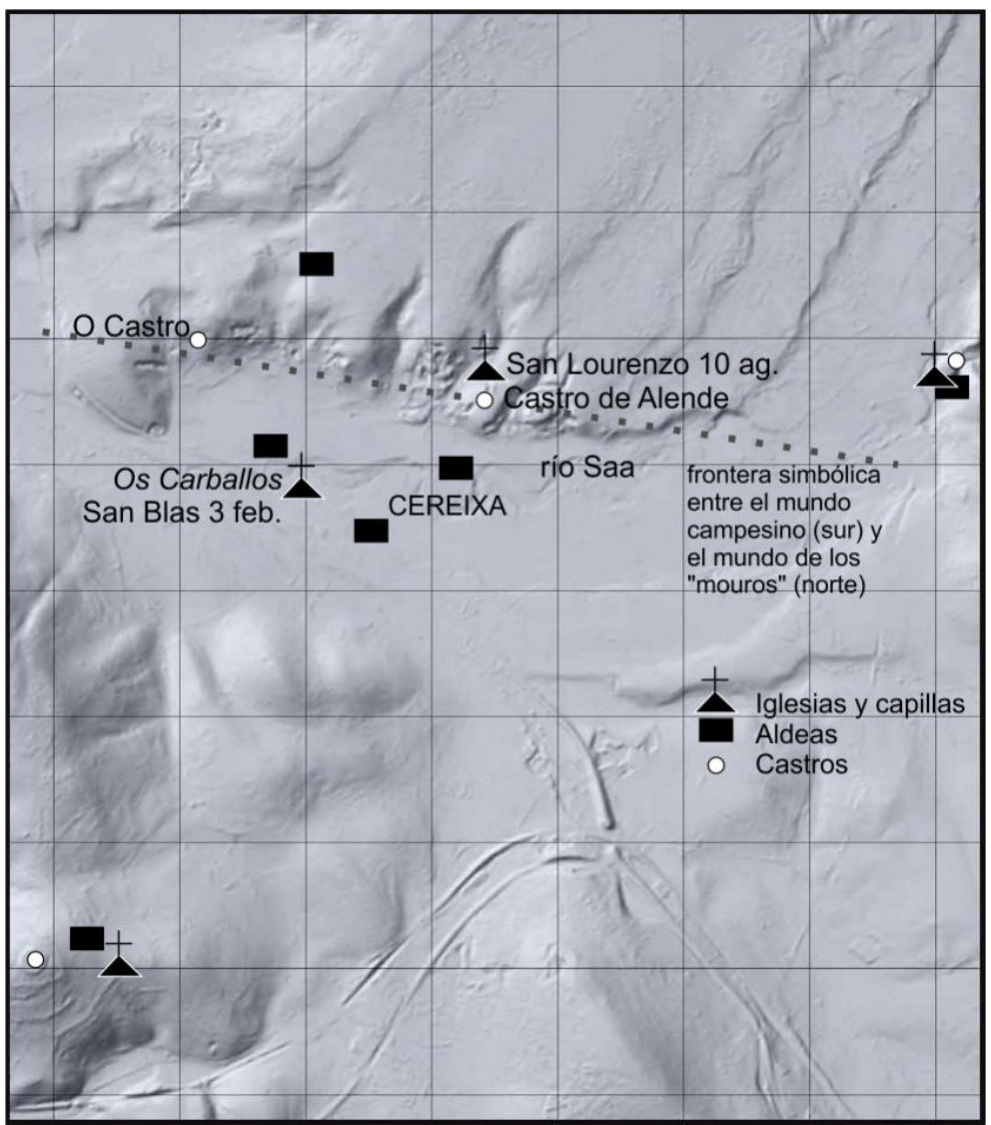

Fig. 9. Paisaje dual de San Pedro de Cereixa. El paisaje de la parroquia se articula en una serie de dualidades: espacio campesino del valle, espacio "mágico" de las lomas septentrionales; tiempo de San Lorenzo en verano, de San Blas en invierno con sus ritos asociados (de agua y fuego). Todo eso como recuperación y mutación de un paisaje simbólico conformado en la Edad del Hierro.

Fig. 9. The dual landscape of San Pedro de Cereixa. The landscape of the parish is arranged in a series of dualities: the farming areas in the valley, the "magic" area of the northern hills; around the feast day of Saint Lawrence in the summer (August $10^{\text {th }}$ ) and Saint Blaise in winter ( $3^{\text {rd }}$ February) with their associated rituals of water and fire. All this results from the recovery and alteration of a symbolic landscape created in the Iron Age.

(18 de julio) auxiliada por San Pedro (29 de junio).

En Augas Santas la estructura dual está equilibrada por el plano medio formado por la aldea en torno a las fuentes (Fig. 10). A partir de ahí se aprecia la asociación del verano con la parte baja del paisaje local y del invierno con la parte alta. Sin embargo, como ocurría en Cereixa, se detecta cierta paradoja en la ubicación de las aguas refrescantes de Mariña en la parte baja veraniega y del calor de la eira de mallar en la parte alta invernal. La estructura dialéctica que presentamos no se limita a estas manifestaciones.

Otra manifestación se aprecia en las saunas de la Edad del Hierro (recordemos que la cripta de la Basílica de la Ascensión se construye a partir de uno de esos monumentos). El edificio actúa como un intercambiador entre el agua llevada por canalizaciones y el fuego encendido en el horno situado en su parte más profunda para producir el vapor de la sauna. De forma análoga el martirio de Mariña (= agua) en el horno reproduce el fenómeno físico de la sauna y el rescate de San Pedro evoca la vuelta al estado líquido de Mariña/agua en el exterior en la Pioucas donde, según la tradición, siempre hay agua.

Dado que el cristianismo no integra, en principio, una ideología o una cosmovisión dualista, cabe plantearse si los "paisajes duales" presentados son, también, una herencia del pasado. En este sentido cabe indicar el dualismo del calendario celta, articulado entre el sol y la luna, la mitad oscura del año y la mitad clara, y lo mismo ocurre con los meses. Por su parte F. Delpech ha estudiado expresiones duales en el folclore (DELPECH 2010). En este contexto los paisajes duales detectados son, por un lado y en el pasado, el correlato espacial del orden dual del tiempo celta y, por otro lado y en el presente cristiano, la forma de apropiación cristiana de un paisaje construido según esas premisas (más detalles en GARCÍA QUINTELA 2014b). 


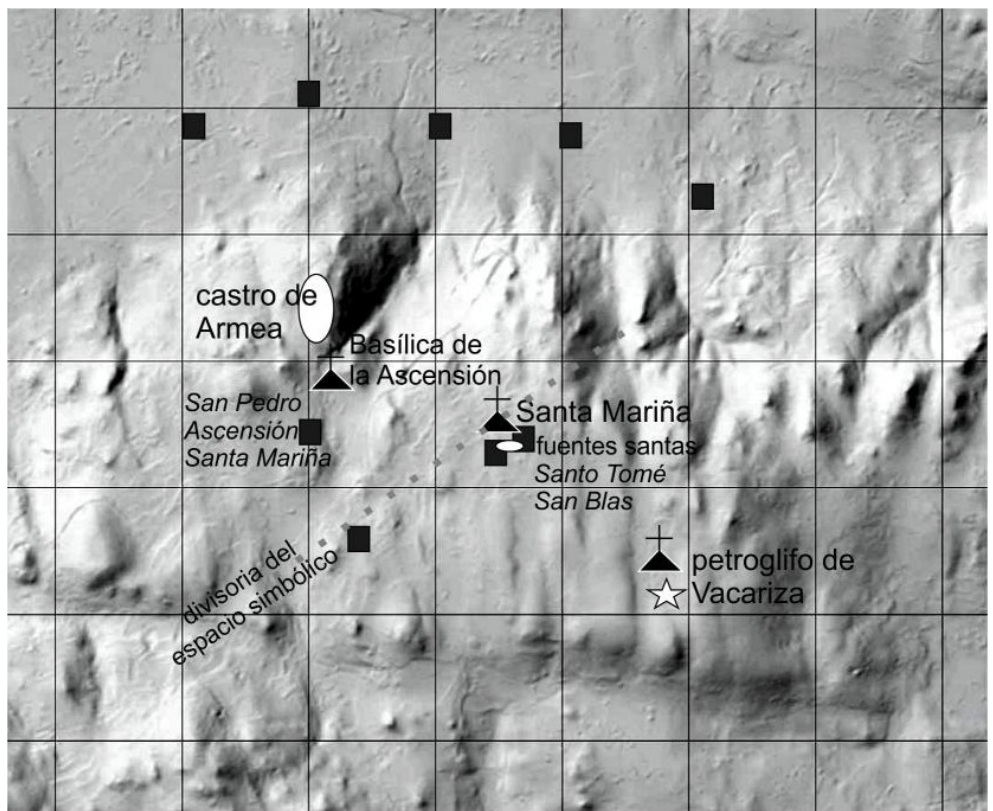

Fig. 10. Paisaje dual de Santa Mariña de Augas Santas. En blanco elementos de la Edad del Hierro, los cuadrados negros son aldeas y caseríos modernos, las cruces los principales lugares de culto cristiano. En este caso las fuentes santas en la aldea de Augas Santas marcan la divisoria del paisaje local en una mitad oeste, baja, de dominante veraniega y otra mitad este, alta, de dominante invernal. En las dos mitades se producen juegos de oposición entre agua y fuego.

Fig. 10. The dual landscape of Santa Mariña de Augas Santas. In white, elements from the Iron Age. The black squares are modern villages and hamlets; crosses indicate the main places of Christian worship. In this case, the holy fountains in the village of Augas Santas mark the boundary in the local landscape between a low, westerly, summertime half and a high, easterly, wintertime half. In these two halves there is an interplay between water and fire.

\section{SANTA MARIÑN COMO SÍNTESIS}

De forma general los métodos son las herramientas necesarias para ejercer un oficio. Se trata de usar la herramienta adecuada para cada tarea y si imaginamos una tarea para la que no tenemos una herramienta adecuada, diseñamos una nueva. En las páginas precedentes hemos hecho esto último al implementar un método sintético entre la arqueología del paisaje y la lectura estratigráfica de los cristianismos locales para comprender cómo se transforman las estructuras religiosas de la Edad del Hierro. Para otros puntos hemos utilizado otras herramientas.

La crítica histórica y literaria ha servido para identificar los motivos concordantes entre las historias cristianas de viajes al Más Allá y de ciudades sumergidas con tradiciones celtas y hemos bosquejado un análisis de mitología comparada para indicar la presencia de motivos celtas en la historia de Santa Mariña. Además, un somero análisis estructural nos ha permitido identificar la dialéctica subyacente en la organización simbólica del espacio en dos parroquias de Galicia sin relaciones aparentes. Sin embargo parece que esa estructura responde a una forma de pensamiento a la vez antigua y poderosa. Merece la pena detenernos un poco más en Santa Mariña porque sobre ella hemos aplicado tres métodos de análisis.
1. La arqueología del paisaje y la estratigrafía cristiana nos ha permitido observar un calendario de horizonte de la Edad del Hierro y su compleja reinterpretación cristiana.

2. El análisis estructural ha mostrado la dialéctica dualista que organiza la parroquia de Augas Santas como comunidad social y la ladera del monte dos Canteiros como ente físico.

3. La mitología comparada sugiere la raíz celta de algunos de motivos presentes en la historia de Mariña.

En todo caso debe quedar claro nuestro problema: averiguar qué herramienta(s) es(son) más adecuada(s) para comprender la cristianización del paisaje de Augas Santas y usar tres (sin excluir que puede haber otras) que nos proporcionan explicaciones distintas y complementarias. Pero otra cosa era el problema de los cristianos que dieron sentido a esa parcela del territorio y construyeron sus argumentos al tiempo que actuaban también sobre los restos materiales preexistentes. Esta es la última idea que podemos subrayar.

Los cristianos que emprenden la tarea de implantarse en el medio rural para erradicar el paganismo llevaron a cabo una lectura global del paisaje con un éxito notable y duradero. Conviene insistir, también, en que la negociación con la realidad preexis- 
tente no supuso una sumisión, no supuso su aceptación pasiva. La posición del cristianismo que se expande por los campos era fuerte, partía de arriba en la escala social y de las ciudades en el plano espacial y administrativo, era creativa, pues estaba respaldada por una tradición ya multisecular con herramientas de evangelización bien conocidas y aplicadas del modo más conveniente para sus intereses. Es decir, el cristianismo triunfante no asumía y encauzaba "supervivencias" del pasado sino que incidía activamente sobre ese pasado, reinterpretándolo o manipulándolo a su modo para construir un paisaje que, desde entonces, es el paisaje cristiano de Galicia. Ese es el problema histórico que hemos intentado abordar.

Sin duda nos faltan las fechas. En algunos casos hemos podido situar el posible origen de los procesos descritos en la Alta Edad Media. Pero en la estructura del volumen en el que se inscribe esta aportación las dataciones se aportan en otras contribuciones. Sólo considerando de forma global las transformaciones estudiadas a lo largo del volumen, como son las variaciones en el paisaje agrario, los usos del suelo y su derivada de los usos alimenticios, podemos comprender el interés que define la nueva percepción del territorio que supone la introducción del cristianismo. El estudio del cristianismo naciente en Gallaecia no es, por lo tanto, el estudio de una forma epidérmica o ideológica, superestructural si utilizamos la vieja terminología marxista. El estudio de la construcción del paisaje cristiano es el estudio de las formas actualmente visibles de un cambio muy profundo que alcanza a los patrones de uso del territorio (abandono de los castros, construcción de aldeas en las tierras de cultivo junto a las iglesias, construcción de terrazas agrarias), a la modificación de la cubierta vegetal (deforestación masiva), a la aparición de nuevas formas de vida social (élite eclesial y nuevos señores cristianos) y a la aparición de nuevos flujos económicos (un sistema impositivo que permite la canalización de excedentes hacia la construcción de las formas físicas de esas transformaciones: hay iglesias donde nunca hubo santuarios "a la romana", pero sí santuarios rupestres de tradición prerromana).

\section{BIBLIOGRAFIA}

ARmada PITA, X.L. 2003. El Culto a Santa Eulalia y la cristianización de Gallaecia : algunos testimonios arqueológicos. Habis, 34: 365-388.

AYÁN VILA, X. 2005. Etnoarqueoloxia e microhistoria dunha paisaxe cultural: a parroquia de San Pedro de Cereixa (Pobra de Brollón, Lugo). Cuadernos de Estudios Gallegos, 52: 117-172.

Blanco Rotea, R.; Mañana BorrazÁs, P.; Mato Fresán, C.; Rodríguez Costas, A. 2009. La Basílica de la Ascensión y Os Fornos (Allariz, Ourense). Revista Aquae Flaviae 41: 467 -477.

CArré AldaO, E. 1925. A Lênda de San Amaro o pelengrino. Nós, 19, julio: 6-10.
Carrera Ramírez, F.; Costas Goberna, F.J. \& Peña SANTOS, A. DE LA. 2002. Grabados Rupestres en Galicia. Pontevedra, Diputación.

CRIADO BoAdo, F. 1999. Del Terreno al Espacio: planteamientos y perspectivas para la Arqueología del Paisaje. Santiago de Compostela, USC.

Criado BoAdo F; Martínez Cortizas, A. \& García QuinTElA, M.V. (eds.) 2013. Petroglifos, paleoambiente y paisaje. Estudios interdisciplinares del arte rupestre de Campo Lameiro. Madrid, CSIC, http:// libros.csic.es/product_info.php?products_id $=640$

De Bernardo, P.; García Quintela, M.V. 2008. Población trilingüe y divinidades del castro de Lansbriga (NO de España). Madrider Mitteilungen, 49: 254-290.

De Polignac, F. 1985. Argos entre centre et périphérie : l'espace cultuel de la société grecque. Archives de Sciences Sociales des religions, 59/1: 55-63.

De Polignac, F. 1995. La naissance de la cité grecque. Cultes, espace et société. París, La Découverte.

DELPECH, F. 2010. Le trésor et la clef : de la mythologie celtique au folklore de l'or caché dans les traditions ibériques. In: F. Burillo MOZOTA (Ed.), VI Simposio sobre celtiberos. Ritos y Mitos. Daroca y Zaragoza, Centro de Estudios Darocenses e Institución Fernando el Católico: 523-40.

DÍAZ Y DÍAZ, M. C. 1992. La cristianización en Galicia. In: F. Acuña CAstroviejo (Ed.), La romanización de Galicia. Sada (A Coruña), Cuadernos del Seminario de Estudios Cerámicos de Sargadelos 16: 105-120.

DÍAZ Y DÍAZ, M.C.; PARdo GÓMEZ, M.V. \& VILARIÑo PINTOS, D. 1990. Vida y Milagros de San Rosendo Ordoño de Celanova. A Coruña, Fundación Pedro Barrié de la Maza.

DíAZ y DíAZ, M. C. 1985. Un viaje a la isla del paraíso. In: M.C.Díaz y Díaz (éd.), Visiones del más allá en Galicia durante la Alta Edad Media. Santiago, Bibliófilos Gallegos: 95-112.

DíAZ Y DíAZ, M. C. 1997. Valerius du Bierzo, Lettre sur la Bse Égérie. Introduction, texte et traduction par ... In: P. MARAVAL, Égérie, Journal de voyage (Itinéraire). Introduction, texte critique, traduction, notes, index et cartes... Paris, éd. du Cerf: 321 -349.

DOWNDEN, K. 2000. European Paganism. The realities of cult from antiquity to the Middle Ages. Londres, Routledge.

Ferro Couselo, J. 1952. Los petroglifos de término y las insculturas rupestres de Galicia. Orense, Talleres gráficos de Miguel López Elizalde.

GARcía Alonso, J. L. 2006. -briga Toponyms in the Iberian peninsula. e-Keltoi. Journal of Interdisciplinary Celtic Studies. 6: The Celts in the Iberian Peninsula: 689714.

García QuinTEla, M.V. 2007. Le Pendu et le noyé des monts Albains. Recherches comparatives sur les mythes et rites des Monts Albains. Bruselas, Latomus.

García Quintela, M.V. 2014a. Marina concubina, Marina virgen, Boand adúltera: fecundidad extramarital y creación de paisajes. In: $\mathrm{M}^{\mathrm{a}}$ Tausiet, H. Tropé (eds.), Folclore y leyendas en la península ibérica. En torno a la obra de François Delpech. Madrid, CSIC: 57-80.

García QuinTELA. M.V. 2014b: Paisajes duales en la Galicia tradicional: estructura, génesis y transformación. Revista de Dialectología y Tradiciones Populares, 69(1): 29-52. 
García Quintela, M.V.; GonZÁlez García, A. C. 2009 Arqueoastronomía, Antropología y Paisaje. Complutum, 20(2): 39-54

García Quintela, M.V.; SANTos EstéveZ, M. 2008. Santuarios de la Galicia Céltica. Madrid, Abada.

García Quintela, M.V.; SeOAne Veiga, Y. 2011. La larga vida de dos rocas orensanas. Archivo Español de Arqueología, 84: 241-264.

García Quintela, M.V.; SeOAne Veiga, Y. 2013. Entre Naturaleza y cultura: La arquitectura Ambigua en la Edad del Hierro del Noroeste de la Península Ibérica. Gallaecia, 32: 47-86.

García Quintela, M.V.; GonZÁlez García, A. C. \& SeOANE-VEIGA, Y. 2014. De los solsticios en los castros los santos cristianos: la creación de los paisajes cristianos en Galicia. Madrider Mitteilungen, 55: 443-485.

García Rollán, M. 2004. Hitos importantes en la excavación de Castromao (Coeliobriga). Boletín Auriense, 34: 9-14.

GonzÁlez Ruibal, A. 2006-2007. Galaicos. Poder y comunidad en el Noroeste de la Península Ibérica (1200 a.C. -50 d.C.). 2 vols. A Coruña, Brigantium

GRøNLIE, S. 2006. Íslendingabók - Kristni Saga. The Book of the Icelanders - The Story of the Conversion, traducidos y comentados por ... Londres, Viking Society for Northern Research.

GuERrA, A. 2005. Povos, cultura e língua no ocidente peninsular: uma perspectiva, a partir da toponomástica. Acta Palaeohispanica IX. Palaeohispanica, 5: 793-822.

GuYONVARC'H, Ch.-J. 1980. Textes Mythologiques Irlandais I. Rennes, Celticum.

LAFAYE, J. 1977. Quetzalcóatl y Guadalupe: la formación de la conciencia nacional en México. México, Fondo de Cultura Económica.

LAJOYE, P. 2003. Les navigations et l'âme celte dans l'antiquité. Ollodagos, 18: 3-39.

Le Roux, F.; Guyonvarc'H, Ch.-J. 1995. Les fêtes celtiques. Rennes, Ouest-France.

LÉVI-STRAuSS, C. 1973. Anthropologie structurale deux. París, Plon.

LIMIA GARDÓN, F.J. 1987. Santa Mariña de Augas Santas, Ourense : aproximación a su estudio durante el Siglo de las luces. Boletín de estudios del Seminario "Fontán-Sarmiento" de hagiografia, toponimia y onomástica de Galicia, 9: 17-22.

MARCo SimÓN, F. 1994. Heroización y tránsito acuático: Sobre las diademas de Mones (Piloña, Asturias). In: J. Alvar, J. Mangas (eds.), Homenaje a J.M. Blázquez, II. Madrid, Clásicas: 319-348.

MARCo Simón, F. 2009. Iconografia y mito en la Hispania céltica: la vía acuática al allende. In: F. Delpech \& M.V. García Quintela (eds.), Vingt ans après Georges Dumézil (1898-1986). Budapest, Archaeolingua: 211-225.
MuÑoz DE LA CueVA, J. 1726 (2008). Noticias históricas de la Santa Iglesia Cathedral de OrenseBreve compendio de la vida y martyrio de la Gloriosa Virgen y Martyr Sta. Marina. A Coruña, Órbigo.

Nieto MuÑIz, E.B. 2002. Novo aspecto da Tabula Hospitalis de Castromao. Boletín Auriense, 32: 53-74.

NúÑEZ GarcíA, O.; CAVAdA Nieto, M. 2001. El Nacimiento del cristianismo en Gallaecia: manifestaciones pagano-cristianas en los siglos I-IV. Ourense, Aica.

Orero Grandal, L. 2000. Castromao (Celanova, Ourense). Brigantium, 12: 179-186.

Peña Santos, A. De la; Rey García, J.M. 2001. Petroglifos de Galicia. A Coruña, Vía Láctea.

Peña Santos, A. De la; VÁzquez Varela, J.M. 1996. Lo Petroglifos Gallegos. Sada (A Coruña), O Castro.

PÉREZ LOSADA, F. 2002. Entre a cidade e a aldea : estudio arqueohistórico dos "aglomerados secundarios" romanos en Galicia. Brigantium, 13.

SÁNCHEZ, J.-P. 1997. San Borondon, San Amaro y el paraíso atlántico. Grial, 35/136: 623-638.

Santos Estévez, M. 2007. Petroglifos y Paisaje Social en la Prehistoria Reciente del Noroeste de la Península Ibérica. Madrid, CSIC.

SAntos Estévez, M. 2008. A New Proposal for the Chronology of Atlantic Rock Art in Galicia(NW Iberian Peninsula) In: G. Nash; G. Children (eds.) The Archaeology of Semiotics and the Social Order of Things. Oxford, BAR IS 1833: 141-152.

Sauzeau, P. 2005. Les Partages d'Argos. Sur les pas des Danaïdes. París, Belin.

Seoane-Veiga, Y.; García Quintela, M.V.; GüImil FARIÑA, A. 2013. Las pilas del Monte de Santa Mariña de Maside (Ourense): hacia una tipología de los lugares con función ritual en la Edad del Hierro del NW de la Península Ibérica. Cuadernos de Estudios Gallegos, 60(126): 13-50.

TABonda Chivite, J. 1969. Las Leyendas de la Laguna Antela. Cuadernos de estudios gallegos, 24 (72-74): 348-362.

TILlEy, Ch. 1994. A Phenomenology of landscape, Oxford, Berg.

VALDÉS, L. 2005. El Santuario Protohistórico de Gastiburu (siglos IV al I a.C.) y el calendario estacional (Arratzu, Bizkaia). Munibe, 57: 333-343.

VegA, C.A. 1987. Hagiografia y literatura. La vida de San Amaro. Madrid, El Crotalón. 